\title{
A importância da seguridade e qualidade microbiológica e parasitológica em
}

\section{hortaliças}

\author{
The importance of microbiological and parasitological safety and quality in vegetables \\ La importancia de la seguridad y calidad microbiológica y parasitológica en hortalizas
}

Recebido: 09/10/2021 | Revisado: 18/10/2021 | Aceito: 25/10/2021 | Publicado: 27/10/2021

\author{
Daniel Barbosa da Silva \\ ORCID: https://orcid.org/0000-0002-7745-0267 \\ Faculdade Integrada Carajás, Brasil \\ E-mail: barbosa9553@gmail.com \\ Carlos Eduardo Almeida Fernandes de Siqueira \\ ORCID: https://orcid.org/0000-0002-8568-0281 \\ Faculdade Integrada Carajás, Brasil \\ E-mail: kadusikeira@gmail.com \\ Jânio Sousa Santos \\ ORCID: https://orcid.org/0000-0003-2180-1109 \\ Faculdade Integrada Carajás, Brasil \\ E-mail: santosjs.food@gmail.com
}

\begin{abstract}
Resumo
O objetivo do presente estudo foi uma revisão bibliográfica do estado atual e dos últimos anos de alimentos frescos como as hortaliças, sendo em sua maioria alface e couve consumidos in natura, dando ênfase a estudos de periódicos publicados nos últimos 20 anos considerando a presença de microrganismos como a coliformes a $45^{\circ} \mathrm{C}$, Salmonella ssp, e variados fungos. O consumo de alimentos in natura nas últimas décadas sofreu um aumento considerável, por conta da busca pelo conhecimento da origem dos alimentos consumidos, principalmente em hortaliças. Em pequenas cidades o cultivo e comercialização de hortaliças e vegetais é realizada majoritariamente por famílias em suas hortas de pequeno porte, muitas das vezes, a céu aberto e na própria área urbana onde podem existir diversos risco para a produção desses alimentos naturais, como fossas, esgotos abertos e animais de rua, por esse motivo, esses vegetais estão sujeitos a contaminação por microrganismos oportunistas, como os coliformes a $45^{\circ} \mathrm{C}$, Salmonella ssp e fungos. As infecções por decorrência de alimentos são comuns, e denominadas como doenças transmitidas por alimentos (DTAs). As DTAs são doenças que podem levar indivíduos a óbito. Conclui-se, que o controle de qualidade de alimentos está diretamente ligado a saúde, ou seja, um produto com qualidade e seguridade garante que menos surtos por doenças transmitidas por alimentos aconteçam, evitando de forma substancial a sobrecarga nos sistemas de saúde pública.
\end{abstract}

Palavras-chave: Hortaliças; Salmonella ssp; Fungos; Coliformes a $45^{\circ} \mathrm{C}$; Doenças transmitidas por alimentos.

\begin{abstract}
The aim of this study was a literature review of the current status and recent years of fresh foods such as vegetables, mostly lettuce and kale consumed in natura, emphasizing studies from journals published in the last 20 years considering the presence of microorganisms such as coliforms at $45{ }^{\circ} \mathrm{C}$, Salmonella ssp, and various fungi. The consumption of fresh foods in recent decades has increased considerably, due to the search for knowledge of the origin of the foods consumed, mainly in vegetables. In small towns, the cultivation and sale of vegetables and vegetables is mostly carried out by families in their small gardens, often outdoors and in the urban area itself, where there may be various risks for the production of these natural foods, such as septic tanks, open sewers and stray animals, for this reason, these plants are subject to contamination by opportunistic microorganisms, such as coliforms at $45^{\circ} \mathrm{C}$, Salmonella ssp and fungi. Foodborne infections are common and termed foodborne illnesses. These diseases that can lead to death. It is concluded that food quality control is directly linked to health, that is, a product with quality and safety ensures that fewer outbreaks of foodborne diseases occur, substantially avoiding the burden on public health systems.
\end{abstract}

Keywords: Vegetables; Salmonella ssp; Fungi; Coliforms at $45^{\circ} \mathrm{C}$; Foodborne illnesses.

\section{Resumen}

El objetivo de este estudio fue hacer una revisión de la literatura sobre el estado actual y los últimos años de alimentos frescos como verduras, mayoritariamente lechuga y col rizada consumidos in natura, enfatizando estudios de revistas publicadas en los últimos 20 años considerando la presencia de microorganismos como coliformes en $45^{\circ} \mathrm{C}$, Salmonella ssp y diversos hongos. El consumo de alimentos frescos en las últimas décadas se há incrementado considerablemente, debido a la búsqueda del conocimiento del origen de los alimentos consumidos, principalmente en 
hortalizas. En los pueblos pequeños, el cultivo y venta de hortalizas y hortalizas lo realizan mayoritariamente las familias en sus pequeños huertos, muchas veces al aire libre y en el propio casco urbano, donde pueden existir diversos riesgos para la producción de estos alimentos naturales, como pozos sépticos, alcantarillas abiertas y animales callejeros, por esta razón, estas plantas están sujetas a contaminación por microorganismos oportunistas, como coliformes a $45^{\circ} \mathrm{C}$, Salmonella ssp y hongos. Las infecciones transmitidas por los alimentos son comunes y se denominan enfermedades transmitidas por los alimentos. Estas son enfermedades que pueden provocar la muerte. Se concluye que el control de la calidad de los alimentos está directamente ligado a la salud, es decir, un producto con calidad y seguridad asegura que se produzcan menos brotes de enfermedades transmitidas por alimentos, evitando sustancialmente la carga sobre los sistemas de salud pública.

Palabras clave: Hortalizas; Salmonella ssp; Hongos; Coliformes a $45^{\circ} \mathrm{C}$; Enfermedades transmitidas por los alimentos.

\section{Introdução}

Nas últimas décadas a busca por uma vida saudável têm crescido exponencialmente devido a mudança do padrão social relacionada a globalização. Por conta dessa crescente a busca por produtos naturais sem conservantes e sem aditivos tem aumentado, com destaque para os vegetais, como hortaliças e frutas em geral os quais se tornaram cada vez mais valorizados. Outro fator que levam a sociedade a buscar formas de alimentação mais saudáveis são os problemas de saúde relacionados a má alimentação por meio de alimentos industrializados, sendo eles embutidos ou enlatados (Martins, Vieira, Machado, Gregório \& Amaral, 2021). As hortaliças verdes apresentam uma grande quantidade de nutrientes, fibras e sais minerais de cálcio e ferro, além de vitaminas da classe B1, B2, B6, vitamina C e provitamina A (Keskinen, Burke \& Annous, 2009).

Em pequenas cidades o cultivo e comercialização de hortaliças e vegetais é realizado majoritariamente por famílias em suas hortas de pequeno porte, muitas das vezes, a céu aberto e na própria área urbana onde podem existir diversos risco para a produção desses alimentos naturais, como fossas, esgotos abertos e animais de rua. Por esse motivo, o cultivo se torna propicio para a contaminação de agentes microbiológicos e parasitológicos. Os principais agentes infecciosos nessas situações são: os Coliformes termotolerantes e a Salmonella ssp., os dois agentes são comuns em hortas.

Por se tratar de pequenos cultivos familiares, a utilização de produtos industrializados como fertilizantes é reduzida, no lugar desses, a forma mais usual de fertilização é realizada por meio de adubos naturais, como por exemplo o esterco animal (bovinos e galináceos). Esse tipo de fertilização pode ser um meio de contaminação pois, os Coliformes termotolerantes e a Salmonella ssp. são transmitidos pela rota fecal-oral, e por esse motivo podem ser facilmente encontrados nesse tipo de adubo (Abreu, Junqueira, Peixoto \& Oliveira 2010; Franco \& Landgraf, 2001).

As infecções por decorrência de alimentos são comuns, e denominadas como doenças transmitidas por alimentos (DTAs). As DTAs são doenças que podem levar indivíduos a óbito. Desta forma, fica notório que o controle de qualidade de alimentos está diretamente ligado a saúde. É valido destacar que há a possibilidade de se ter surtos de infecção e/ou intoxicações alimentares em um número elevado de pessoas. Por essa razão, ao assegurar a qualidade e segurança dos alimentos, também está sendo assegurada a saúde, em alguns casos, não somente de uma pessoa, mas de uma comunidade inteira. A presença de Salmonella ssp por exemplo, em alimentos de alto consumo, como as hortaliças, podem gerar surtos de Salmonelose à uma comunidade. Esse agente é uma das principais causas de surtos infeciosos em vários países. A ocorrência de surtos de doenças infecciosas é um grave problema para a rede pública de saúde, podendo até causar sobrecarga no sistema (Shinohara, et al., 2008).

As DTAs podem ser ocasionadas por diversas fontes, como, as bactérias já citadas, vírus e parasitas, o número exato de DTAs não é definido, porém acredita-se que exista mais de 250 tipos diferentes. O surto alimentar causando DTA vem aumentando a nível mundial de forma acelerada, esse aumento pode estar relacionado a diversos fatores, como a necessidade da produção de alimentos em grande escala, por decorrência do aumento da população mundial, controle de qualidade deficiente dos órgãos públicos e privados, a exposição do alimento em ambientes não controlados como bancas de comida ao 
ar livre, feiras livres e os próprios fast foods, a facilidade de deslocamento entre estados e países. Todos esses fatores contribuem para o aumento dos surtos (Lanza, 2017).

Por muitas vezes a busca pelo maior lucro possível tem como consequência um produto final mal-acabado ou de má qualidade. No plantio de hortaliças não é diferente, os pequenos horticultores tendem a buscar de alguma maneira um lucro maior. Essa redução de custos pode estar diretamente ligada a qualidade dos vegetais vendidos. O risco está nestes fatores da seguinte maneira: na preparação do solo os produtores podem optar por não realizar de maneira correta a limpeza do ambiente, a retirada de detritos ou dejetos humanos, permanecer numa localidade onde o plantio seja próximo a esgotos a céu aberto, ou ao lado de foças de suas próprias casas. No ato de regar o plantio, visando a economia pode se optar por utilizar água não potável, o que pode aumentar a possibilidade de uma contaminação por fungos e bactérias advindos desta fonte de água irregular. $\mathrm{O}$ armazenamento e transporte são fatores fundamentais para manter o produto pronto para o consumo fresco, portanto, são ações que tem de ser realizadas com cuidado de maneira correta.

Diante do apresentado o objetivo do presente estudo foi sintetizar uma revisão integrativa do estado atual e dos últimos anos de hortaliças, sendo em sua maioria alface e couve consumidos in natura, dando ênfase a estudos de periódicos publicados nos últimos 20 anos considerando a presença de microrganismos como a coliformes a $45^{\circ} \mathrm{C}$, Salmonella ssp, e variados fungos.

\section{Metodologia}

O estudo se baseou-se por meio de uma revisão integrativa de publicações científicas indexadas nas bases de dados: SCIELO, ANVISA, Ministério Da Saúde do Brasil, BJHR, baseando-se no artigo de Ercole, Melo \& Alcoforado (2014) como modelo afim de elaborar uma revisão integrativa. Utilizou-se como base de pesquisa publicações nas línguas inglesa e portuguesa, e como termos de busca Salmonella, coliformes a $45^{\circ} \mathrm{C}$, fungos em alimentos, hortaliças, e doenças transmitidas por alimentos. Contudo, utilizou-se a técnica para o desenvolvimento e separação das informações de acordo com cada base de dado. O intervalo de tempo para aceitação das publicações foi equivalente a 20 anos (2001 - 2021). Os artigos utilizados para a comparação de pesquisa foram exclusivamente brasileiros, além de discutirem sobre hortaliças. A busca pelas informações foi realizada por acesso online, selecionados pelos autores e revisados pelos mesmos, sempre considerando os critérios de exclusão e inclusão.

\section{Resultados e Discussão}

\section{Comercialização de hortaliças}

No Brasil, a agricultura orgânica desde de o seu princípio, era voltada para hortigranjeiros, ou seja, produtos resultantes de hortas como legumes e hortaliças. A comercialização desses produtos, originalmente era feita de duas formas, as famosas feiras livres são uma alternativa, locais onde inúmeros comerciantes de tamanhos variados se reúnem para atrair o público para o mesmo lugar, e a outra era as entregas direto a domicilio (Assis \& Romeiro, 2007).

O tempo passa e algumas coisas acabam mudando, como os supermercados começaram a dar mais importância para esses produtos naturais. No estudo de Assis e Romeiro (2007), alguns dados importantes foram levantados, como uma divisão do tipo de produtor em empresa familiar, contendo 13 representantes e empresa de gerencia familiar com 19, os números mostram que apenas 8 empresas destes dois grupos fazem a comercialização de forma majoritária nas feiras livres, as outras 24 empresas vendem seus produtos para os supermercados revenderem. 


\section{Contaminação de alimentos}

O manipulador de alimentos é de suma importância na prevenção das doenças transmitidas por alimentos, pois, essas doenças são causadas geralmente por microrganismos oportunistas, esses, por sua vez na primeira falha sanitária podem contaminar um alimento em questão. No caso dos alimentos crus a situação é ainda pior, pelo fato de que esses são consumidos normalmente frescos e sem passarem por processamentos (Andreotti, Baleroni, Paroschi \& Panza, 2003). Os mesmos autores ainda afirmam que, o manipulador de alimentos é uma classificação bem ampla de trabalhadores, pelo motivo de que o mesmo engloba todo e qualquer pessoa que tenha contado com parte do alimento, como os que colhem, abatem, armazenam, transportam, processam ou preparam. Na maioria dos casos o manipulador não possui noção do perigo que a contaminação biológica representa, e muito menos de como evitá-la, isso pode ser uma consequência da falta de conhecimento e preparo qualificado para exercer o papel de manipulador de alimentos.

A produção de alimentos no âmbito agrícola de pequeno porte é comum no Brasil, esse tipo de produção precisa ser realizado seguindo diversos cuidados, pois as frutas e hortaliças podem ser contaminadas por microrganismos durante a própria produção como em casos de irrigação com água contaminada, ou até mesmo na utilização de esterco não curtido como fertilizante, em ambos os casos existe o alto risco do agente infecioso ser a Salmonella. Com isso fica evidente a necessidade de cuidado com os materiais utilizados no processo de germinação dessas plantas. Evitar a contaminação é o melhor caminho a ser seguido, uma vez que os agentes desinfetantes possuem limites em sua capacidade de destruição, as vezes não sendo o suficiente para livrar completamente o alimento de sua contaminação (Nascimento Neto, 2006).

Muitas vezes os pequenos produtores não realizam vendas de seus produtos para os consumidores finais, mas sim, para pessoas que adquirem estes produtos para revenda, e nesse caso sim, será para o consumidor final. Num sistema como esse, na maioria das vezes o revendedor possui mais de um fornecedor, podendo ser até do mesmo produto, isso abre a possibilidade de uma contaminação cruzada, onde um único produto contaminado possui a capacidade que contaminar todos os outros, dessa forma ocasionando o início de um surto de uma doença transmitida por alimentos.

Os alimentos produzidos por agricultores de pequeno porte estão sujeitos a contaminação oriunda de diversas fontes, como o próprio solo onde as plantas geralmente passão toda a sua vida, produzindo frutos ou folhas contaminadas. Os amimais também são uma forma de contaminação para a produção, pois alguns desses microrganismos possuem a capacidade de transitar entre animais e humanos, esses sendo classificados como zoonoses, sendo assim, as hortaliças produzidas em um meio onde animais de diversos tipos conseguem transitar livremente, podem fazer o papel de mediador para uma determinada zoonose (Nascimento Neto, 2006).

Cada alimento possui suas próprias características naturais, também chamadas de parâmetros intrínsecos, esses são muito específicos, como o pH e a atividade de água $(\mathrm{aW})$, esses dois fatores podem contribuir para a proliferação de alguns microrganismos, além de possuírem a capacidade de limitar o mesmo isto é possível pois ambos são variáveis de acordo com o próprio alimento. Um bom exemplo é a Escherichia coli, que por sua vez para conseguir realizar sua multiplicação necessita que o pH do alimento esteja entre 4,4-9,9. O fator aW também possui um valor mínimo para que haja a possibilidade de proliferação desse microrganismo, sendo de 0,95 , ou seja, um valor bem elevado na escala de aW, que vai de 0 a 1 (Hoffmann, 2001).

Os microrganismos contaminantes por muitas vezes necessitam de condições adequadas para conseguir se desenvolver e se proliferar, isso ocorre normalmente após a colheita, onde muitas condições exigidas pelos contaminantes podem ser atingidas, como o manuseio inadequado que pode acabar levando a uma contaminação cruzada, que é basicamente quando a contaminação é transferida de uma hortaliça contaminada para uma saudável. A temperatura também possui um papel muito importantes na proliferação de microrganismos contaminantes, esse mecanismo de temperatura pode acabar funcionando como catalisador no crescimento de microrganismos. A contaminação de um alimento in natura pode significar a 
deterioração do mesmo, causando uma mudança nos aspectos sensoriais, como mudança de cor - isso ocorre na maioria dos casos - o cheiro também pode ser afetado, além da própria textura do alimento, e claro o sabor do mesmo pode e geralmente é drasticamente alterado (Nascimento Neto, 2006).

$\mathrm{O}$ pH é muito importante para o desenvolvimento de vários tipos microrganismos, sendo assim os alimentos possuem uma classificação, indo do $\mathrm{pH}>$ 4,5 (alimentos pouco ácidos), $\mathrm{pH}$ entre 4 e 4,5 (alimentos ácidos), pH < 4 (alimentos muito ácidos). Os alimentos pouco ácidos são propensos ao desenvolvimento da maioria das bactérias inclusive as patógenas, além dos bolores e leveduras. Nos alimentos ácidos a grande maioria dos microrganismos patógenos não conseguem se proliferar, porém, para os bolores e leveduras esse nível de pH é perfeito para o crescimento. Em alimentos muitos ácidos o crescimento de microrganismos é restringido as leveduras e bolores (Hoffmann, 2001).

\section{Padrões sanitários exigidos para hortaliças}

A prevenção que o manipulador dever exercer baseia-se na higiene pessoal, como manter unhas limpas, assim como o cabelo, boca, orelhas, dentes e os pés. Evitar o uso de cosméticos na hora da manipulação, não deixar ferimentos expostos, lavar periodicamente o uniforme de trabalho e o mais importante sempre higienizar as mãos antes de manipular os alimentos (Andreotti, Baleroni, Paroschi \& Panza, 2003).

O limite microbiológico pode ser dividido em duas classes, as amostras de "qualidade aceitável" e "qualidade inaceitável", além de uma terceira a "qualidade intermediaria", como o próprio nome sugere, essas classes determinam se o alimento é seguro ou não. Isso é realizado por meio de testes microbiológicos e parasitológicos para identificar se há a presença de microrganismos nocivos. Os microrganismos ou seus metabolitos por sua vez podem ser prejudiciais ao ser humano, porém, isso varia, pois existem muitos deles. Alguns como a Samonella ssp. são inadmissíveis em qualquer quantidade, já os coliformes termotolerantes possuem um limite máximo. E o método para realizar a detecção desses microrganismos é a técnica de número mais provável (NPM) (Brasil, 2019).

Existem diferentes tipos alimentos e cada um possui seus próprios parâmetros, na Instrução Normativa $\mathrm{N}^{\circ} 60$ de 23 de dezembro de 2019, dispõe que as hortaliças não possuem um grupo solo, elas estão juntas às raízes, tubérculos, fungos comestíveis e derivados, esse grupo possui 7 categorias especificas. A primeira classe será o foco pelo fato de que esta estabelece parâmetros microbiológicos para os alimentos in natura. Referente a Salmonella, em 5 amostras da hortaliça não pode existir nem uma com qualidade intermediaria, isso ocorre, pois, para que a amostra possua qualidade aceitável a Salmonella deve estar ausente, então não existe um meio termo. Referente a Escherichia coli, em 5 amostras existe um limite tolerável de 2 amostras com qualidade intermediaria, para a qualidade ser intermediaria o número de Escherichia coli não pode exceder 103 UFC (Unidade Formadora de Colônias), o valor máximo para a qualidade aceitável é 102 UFC, pelos menos 3 amostras do mesmo lote devem obter o resultado aceitável (Brasil, 2019).

No caso que se refere aos bolores e leveduras a primeira categoria não os engloba, porém, eles aparecem na quarta categoria especifica, esta que estabelece parâmetros microbiológicos para alimentos secos ou desidratados. Referente a bolores e leveduras é tolerável que uma das 5 amostras esteja como qualidade intermediaria, essa não pode ultrapassar ao valor de 104 UFC, para as outras 4 amostras que devem possuir qualidade aceitável, o valor que não devem exceder é 103 UFC (Brasil, 2019).

\section{Métodos de higienização dos alimentos vegetais}

Os produtos em geral devem ser higienizados, sejam eles, enlatados, empacotados, a granel, em caixas ou qualquer outra forma, tudo para que os riscos de contaminação sejam reduzidos a um valor próximo a zero. Com alimentos frescos 
cultivados não é diferente, estes, devem ser higienizados e sanitizados para se ter uma garantia de saúde no seu consumo (OMS, 2006).

De acordo com as recomendações do Ministério da Saúde, para manter a segurança ao consumir alimentos, deve-se realizar a desinfecção do alimento, ou seja, eliminar completamente o máximo possível a presença de microrganismos, evitando assim, uma possível contaminação por bactérias ou fungos (Brasil, 2014).

A lavagem é um processo eficiente para realizar a desinfecção, porém, para realizar uma lavagem em hortaliças o processo se torna um pouco mais complexo de que em outros materiais, pois muitos desses produtos não possuem resistência superficial necessária para passar pelo processo, podendo até reduzir sua vida útil em contato com a água. Na lavagem de hortaliças é necessário o uso de métodos específicos que se adequem as caraterísticas de cada alimento, um bom exemplo são frutas macias, onde passam por um processo de higienização, que utiliza aerossol que borrifam a água nas mesmas. No caso de frutas duras como a maçã é possível realizar a lavagem em água corrente. As raízes e tubérculos necessitam de um equipamento exiliar sua limpeza como uma escova macia, que deve ter como única função a higienização destes alimentos, e além disso, deve ser limpa a cada utilização (Nascimento Neto, 2006).

O calor é uma forma de desinfeção de muito eficiente para a eliminação de microrganismos nocivos, logicamente existem alguns microrganismos mais resistentes ao aumento da temperatura que outros, um exemplo interessante é o Salmonella senftenberg $775 w$ que em comparação a outros sorotipos de Salmonella apresenta uma resistência de 10 a 20 vezes maior na presença de calor. Porém, esse método não é viável para as hortaliças (Cardoso \& Carvalho, 2006).

\section{Mecanismo de ação da função sanitizante da solução de hipoclorito de sódio}

O hipoclorito de sódio $(\mathrm{NaOCl})$, é um ótimo meio de higienização de alimentos, pois em baixas concentrações como $1 \%$, a água sanitária possui uma biocompatibilidade aceitável com o corpo humano, fazendo dela inofensiva ao organismo. O hipoclorito de sódio participa da reação de saponificação, e também realiza a neutralização de aminoácidos, e a sua caraterística mais usual é a capacidade de ser um agente antimicrobiano. Um dos motivos para essa ação antimicrobiana é a presença do cloro em sua formulação, por ser um oxidante forte o cloro consegue realizar a oxidação dos grupos sulfidrila de forma irreversível, dessa forma provoca a inibição enzimática bacteriana, levando a mesma a morte (Estrela, et al., 2002).

Outro motivo que destaca ainda mais essa ação antimicrobiana do hipoclorito de sódio são os íons de oxidrila (OH-), que são liberados na síntese de uma solução de $\mathrm{NaOCl}$, um dos resultados dessa união serão os íons de oxidrila como pode ser observado pela relação estequiométrica da reação: $\mathrm{NaOCl}+\mathrm{H}_{2} \mathrm{O}=\mathrm{HOCl}+\mathrm{Na}^{+}+\mathrm{OH}-$. Os íons de $\mathrm{OH}-$ provocam uma grande elevação do pH que por sua vez interfere na integridade da membrana citoplasmática bacteriana, ocasionando em alterações biológicas, além da degradação dos fosfolipídios, resultando numa degradação da barreira, além disso o cloro também garante a inibição enzimática ocasionada pelas citotoxinas produzidas pelas bactérias (Estrela, et al., 2002).

\section{Principais microrganismos contaminantes em alimento}

\section{Salmonella}

A Salmonella é uma bactéria causadora de patologias tanto em humanos quanto em animais, sendo considerada uma zoonose. O meio de contaminação mais comum é o consumo de alimentos contaminados. Os microrganismos desse gênero se multiplicam quando alcançam a camada onde as células epiteliais ficam ancoradas, nesse local os monócitos e os macrófagos fazem o processo de fagocitose, com isso gera uma reação inflamatória como resposta (Shinohara, et al., 2008).

O gênero de bactérias chamadas de Salmonella possuem morfologia de bastonete, e são classificadas como gramnegativas, além de não possuírem a capacidade de formar esporos, conseguem sobreviver em ambientes com oxigênio e sem oxigênio, além serem redutoras de nitratos e nitritos. Sua família é a Enterobacteriaceae (Cardoso \& Carvalho, 2006). 
As infeções causadas por Salmonella são consideradas um problema de saúde pública em todo o mundo, exceto as infeções por S. typhi a mesma causadora da febre tifoide. Os gastos da Dinamarca com a salmonelose alimentar até o ano de 2001 são estimados ente 10 milhões a 25 milhões de dólares, os Estados Unidos também registaram números altos em relação as doenças causadas por Salmonella não tifoide, com mais de 500 mortes por ano, e quase 16.000 hospitalizações. Existem alguns sorotipos de Salmonella responsáveis por esses problemas de saúde pública ao longo do tempo, porém apenas dois se destacam a S. enteritidis e S. typhimurium, essas duas cepas são as causadoras mais recorrentes de salmonelose historicamente falando (Aarestrup, et al., 2007).

A febre tifoide é causada por uma Salmonella, mas não é classificada como uma zoonose, pois apenas o ser humano é infectado, isso ocorre pois não existe apenas uma cepa de Salmonella. Os sintomas da febre incluem septicemia, temperatura alta, diarreias e vômitos, porém existe um fator além dos sintomas onde existe a possibilidade de que algumas pessoas ao serem infectadas permanecem no estado infeccioso por anos sem se dar conta da infecção, o que torna este indivíduo numa fonte contínua de infecção transmissiva. Os óbitos nos casos de febre tifoide geralmente são causados por septicemia (Shinohara, et al., 2008).

Outro exemplo de cepa da Salmonella é a Salmonella paratyphi, esse agente etiológico é o causador da febre entérica que é mais branda em comparação a tifoide, ambas são infecção sistêmicas que agem nos linfonodos mesentéricos, esses são os linfonodos que situam-se dentro de uma parte do corpo chamada mesentério, a partir desse órgão a bactéria se prolifera para outros tecidos e órgãos, por meio da corrente sanguínea (Cardoso \& Carvalho, 2006).

As chamadas Salmonelose são as infecções mais comuns por decorrência de Salmonella sendo a S. enteritidis a cepa causadora de Salmonelose predominante em diversos países. Por tanto, nesses casos, os indivíduos desenvolvem uma infecção no estomago, que causa dores abdominais, diarreia e febres em temperaturas menores baixa. Geralmente no tratamento não é necessário o uso de antibióticos, apenas descanso e ingestão de líquidos, desse modo, levam de dois a três dias a pessoa acometida estará livre da infeção. Diferente da febre tifoide as Salmonelose são classificadas como zoonoses, onde animais e humanos são transmissores em potencial (Shinohara, et al., 2008).

A patogenicidade da Salmonella é variável de acordo com as condições e caraterísticas do próprio hospedeiro, como idade, saúde, além do sorotipo da mesma. Em casos de enterocolites (inflamação do trato digestivo) a Salmonella se prolifera na região da válvula de Bauhin penetrando as células, isso estimula o corpo a produzir uma resposta inflamatória, onde é liberado prostaglandinas, que literalmente provoca o crescimento dos folículos linfoides, por meio do aumento do volume de fibras musculares e o aumento da quantidade das mesmas, esses processos são chamados de hipertrofia e hiperplasia respectivamente, e ocasionando como resposta a diarreia provocada pelo AMP-cíclico (Cardoso \& Carvalho, 2006).

As doenças transmitidas por alimentos, são comuns e principalmente as causadas pelas bactérias do gênero Salmonella, com o tempo era esperado uma diminuição dos casos de infecções por alimentos contaminados, mas o resultado foi contraio, os números de surtos causados por DTAs aumentaram em todo o mundo, ocorrendo até mesmo em países desenvolvidos. Principal causa desses surtos é o sorotipo Salmonella enteritidis. No Brasil não se tem uma noção real do número de casos de salmonelose, como na maioria dos casos de infecção por $S$. enteritidis não se faz necessário a hospitalização pois em seu tratamento não é preciso uma intervenção medicamentosa, por esse motivo nem todos os surtos são notificados pela vigilância sanitária (Cardoso \& Carvalho, 2006).

Na Tabela 1 é apresentado pesquisas relacionadas a presença de Salmonella em diversos tipos de hortaliças, realizados em diferentes cidades e períodos. Com essa pequena comparação é perceptível que todas as pesquisas obtiveram resultados diferentes, isto acontece por variáveis fatores, como região, estabelecimentos, postos de vigilância sanitária, entres outros por menores. As pesquisas que demostraram os resultados mais discrepantes foram de Rocha, de Albuquerque Sousa, de Sousa, Arcanjo, Parreira \& de Oliveira, realizada em 2015 no município de Picos no Piaú, e a de Prado, Ribeiro, Capuano, de 
Aquino, de Melo Rocha \& Bergamini, realizada em 2008 no estado de São Paulo Ribeirão Preto. O motivo dessa discrepância não pode ser definido, porém, uma justificativa plausível seja o local de coleta das amostras, onde no estudo de Rocha foram coletadas em uma feira livre, e no outro estudo as amostras foram coletadas em supermercados.

Tabela 1 - Salmonella comparação de pesquisas feitas no Brasil.

\begin{tabular}{l|l}
\hline Pesquisas & Presença de Salmonella \\
\hline $\begin{array}{l}\text { Rocha, de Albuquerque Sousa, de Sousa, Arcanjo, Parreira \& de } \\
\text { Oliveira, 2015. }\end{array}$ & Todas as amostras. \\
\hline Arbos, Freitas, Stertz \& Carvalho, 2010. & Duas amostras (15,38\% das amostras). \\
\hline Ferreira, Gregório, Costa, de Paula, de Araujo \& Fontes, 2016. & Seis amostras (50\% das amostras). \\
\hline Tresseler, Figueiredo, Figueiredo, Machado, Delfino \& Sousa, 2009. & Dezesseis amostras (12,7\% das amostras). \\
\hline $\begin{array}{l}\text { Prado, Ribeiro, Capuano, de Aquino, de Melo Rocha \& Bergamini, } \\
\text { 2008. }\end{array}$ & Nem uma amostra. \\
\hline
\end{tabular}

Fonte: Autores.

\section{Coliformes a $45^{\circ} \mathrm{C}$}

Os chamados coliformes fecais são aqueles capazes de produzir gases por meio da fermentação da lactose. O exemplo mais comum de um coliforme é a Escherichia coli, a principal diferença dela é sua característica termotolerante, pois ela só é capaz de realizar a fermentação da lactose a $44,5{ }^{\circ} \mathrm{C}$, algumas cepas de Klebsiella e Enterobacter também possuem essa característica (Silva, Cavalli \& Oliveira, 2006). No dia 02 de janeiro de 2001 a ANVISA publicou a RDC nº 12, na qual é afirmado que a denominação "coliformes a $45{ }^{\circ} \mathrm{C}$ " como equivalente a coliformes de origem fecal e coliformes termotolerantes, quando há a presença de Escherichia coli for comprovada (Brasil, 2001).

A presença ou não de coliforme a $45^{\circ} \mathrm{C}$, é um forte indicador das condições sanitárias de lugar como um renomado restaurante, ou até mesmo em comércios localizados em feiras locais ao ar livre. A análise microbiológica de coliformes fecais pode ser utilizada por matadouros e outras empresas do ramo alimentício para determinar as condições sanitárias do local. No gênero dos coliformes existe a família Enterobacteriaceae, que abriga os gêneros Escherichia, Enterobacter, Klebsiella e Citrobacter. A E. coli é uma cepa que possui origem fecal, além de ser a principal representante dos coliformes fecais (Bier, et al., 2017).

O estudo realizado por Silva, Cavalli e Oliveira no ano 2006, demonstrou um resultado curioso em relação às hortaliças em relação aos microrganismos nomeados de coliformes a $45^{\circ} \mathrm{C}$. Na pesquisa 26 amostras foram analisadas e apenas 7 testaram resultado positivo para a presença de coliformes a $45^{\circ} \mathrm{C}$, com os valores de contaminação acima do exigido pela legislação brasileira, porém, em nem uma das amostras coletadas positivaram para $E$. coli, isso indica que nestas hortaliças a contaminação não foi originária pela via fecal, pois essa via de contaminação é confirmada apenas mediante a presença de $E$. coli no alimento (Silva, Cavalli \& Oliveira, 2006).

Afirma-se que a Escherichia coli é o microrganismo facultativo mais abundante presente na microbiota intestinal em seu estado normal, colonizando o trato gastrointestinal, mantendo-se encubada e inofensiva por conta dos agentes de defesa do corpo humano. Porém, quando se trata de um hospedeiro imunodeprimido, a Escherichia coli inicia o processo de multiplicação, onde até mesmo cepas não patogênicas dessa bactéria podem acarretar uma série de problemas infecciosos. Porém, existem cepas de E. coli que se adaptaram e com isso adquirirem atividades com teor de virulência, essas podem até causar doenças no hospedeiro com o sistema inume em perfeito estado de funcionamento. As cepas capazes de provocar enfermidades ao indivíduo são denominadas pathotypes, sua presença pode ser notada por meio de 2 sinais clínicos, diarreia e infecção do trato urinário (Kaper, Nataro \& Mobley, 2004). 
A Tabela 2 mostra os resultados de 5 pesquisas realizadas em território nacional, todas sobre coliformes a $45^{\circ} \mathrm{C}$. A presença desses microrganismos não significa que a hortaliça causará problemas, a menos que os números ultrapassem o limite, um exemplo interessante é a pesquisa de Ferreira, Gregório, Costa, de Paula, de Araujo \& Fontes, realizada no ano de 2016 em Belo Horizonte-MG, todas as suas amostras se apresentaram dentro dos limites estabelecidos pela lei, porém esses também possuíam a presença de coliformes a $45^{\circ} \mathrm{C}$. Na comparação das 5 pesquisas os resultados mostrados são diferentes, isso ocorre de acordo com as variáveis na produção, armazenamento e comercialização dessas hortaliças.

Tabela 2 - Coliformes a $45^{\circ} \mathrm{C}$ comparação de pesquisas feitas no Brasil.

\begin{tabular}{l|l}
\hline Pesquisas & Excederam o limite de coliformes $\mathbf{~ 4 5}^{\circ} \mathbf{C}$ \\
\hline $\begin{array}{l}\text { Rocha, de Albuquerque Sousa, de Sousa, Arcanjo, Parreira, de } \\
\text { Oliveira, 2015. }\end{array}$ & Onze amostras (45,8\% das amostras). \\
\hline Arbos, Freitas, Stertz, Carvalho 2010. & Três amostras (23,07\% das amostras). \\
\hline Ferreira, Gregório, Costa, de Paula, de Araujo, Fontes 2016. & Nem uma amostra. \\
\hline Silva, Cavalli, Oliveira 2006. & Sete amostras (26,9\% das amostras). \\
\hline Teixeira, dos Santos, dos Santos Moreira, de Sousa, Nunes, 2013. & Três amostras (37,0\% das amostras). \\
\hline
\end{tabular}

Fonte: Autores.

\section{Fungos}

Os mofos mais popularmente conhecidos como fungos, são formas de vida caracterizada como eucariontes, pois suas células possuem um núcleo definido, são constituídos por mais de uma célula, porém não conseguem formar tecidos complexos, sendo assim, classificados como multicelulares, além de serem dispostos no formato de filamentos. Os fungos possuem certa ação sobre os alimentos incluindo as hortaliças, como alteração do sabor e odor, porém, em algumas ocasiões isso é um resultado almejado, pois certos tipos de fungos participam de forma fundamental na produção de alguns alimentos, um bom exemplo é o pão caseiro ou industrial, onde o astro e a levedura Sccharomyces cerevisiae faz a fermentação dos açúcares presentes no amido. Os fungos também podem causar resultados muito indesejáveis, por meio da degradação da hortaliça ou outro alimento (Maziero \& Bersot, 2010).

Fungos e leveduras são microrganismos muito versáteis, eles conseguem assimilar carbono de qualquer alimento, o nitrogênio também é facilmente assimilado por eles podendo ser de fontes como o nitrato, amônia e o próprio nitrogênio. As leveduras podem ser consideradas mais exigentes que os bolores, pois elas não conseguem realizar a assimilação do carbono e nitrogênio, quando estes estão presentes em fontes mais complexas, como por exemplo a Zygosaccharomyces bailii, é uma levedura frequentemente associada em casos de infecções gastrintestinais (Silva, et al., 2017).

Bolores e levedura são microrganismos muito resistente em comparação a bactéria por exemplo, quando é avaliado a resistência a pH ácido, pois esses fungos conseguem sobreviver e se proliferar mesmo em ambientes ácidos, com os bolores conseguindo crescer em um $\mathrm{pH}$ de 2, e algumas leveduras levando isso além, se desenvolvendo em ambientes onde o pH atinge 1,5, a velocidade de crescimento nessas circunstâncias extremas é lenta, não sendo comparável a velocidade quando o ambiente está propicio para o desenvolvimento de fungos, que acontece com o pH em torno de 5. Os fungos dificilmente são associados a infecções causadas por alimentos, as causas mais comuns são a leveduras e alguns bolores. As leveduras podem ocasionar reações alérgicas e os bolores acarretam infeções em indivíduos imunodeprimidos. Os gêneros de bolores mais importantes são: Aspergillus, Penicillium e Fusarium (Silva, et al., 2017).

A micotoxinas são metabolitos secundários dos fungos, sendo assim são produzidas pelos mesmos de forma biológica. Existem três gêneros de fungos dominantes na contaminação de alimentos, como frutas, hortaliças e cereais, eles são Aspergillus, Penicillium e Fusarium. Com apenas esses 3 gêneros são produzidos 10 tipos micotoxinas com estruturas 
químicas diferentes, sendo: Aflatoxin G1, Aflatoxin B1, Aflatoxin M1, Deoxynivalenol, Zearalenone, Ochratoxin A, Fumonisin B1, Hydrolyzed Fumonisin B1, Patulin e Ergotamine (Murphy, Hendrich, Landgren \& Bryant., 2006).

A ergotamina, é a micotoxina mais antiga conhecida pelo ser humano, com indícios de surto em 430 a.C. em esparta na Grécia antiga, causando uma doença denominada "St. Anthony’s Fire" com uma tradução ficaria "fogo de santo Antônio", esse nome foi conferido a doença, pois ela causava uma sensação de queimação nos membros do corpo da vítima acometida. A forma comum de contaminação é a ingestão de trigo ou centeio contaminados, nos dias atuais a indústria do ramo alimentício por meio dos programas de controle de qualidade, conseguem identificar os grãos infetados. O último surto de ergotamina conhecido ocorreu em 1978 na Etiópia (Murphy, Hendrich, Landgren \& Bryant., 2006).

\section{Considerações Finais}

O controle de qualidade em hortaliças in natura está diretamente relacionado a saúde pública, por este motivo, as atividades dos postos de vigilância sanitária de fato possuem grande importância, não apenas como agentes de fiscalização dos alimentos, mas também para garantir que os produtores desses produtos realizem as atividades de cultivo de forma ideal e correta, ocasionando assim um alimento seguro para consumo, melhorando a qualidade de vida àqueles que fazem o uso deste. Por fim, afirma-se que por meio de um produto com qualidade e seguridade garante que menos surtos por doenças transmitidas por alimentos aconteçam, evitando de forma substancial a sobrecarga nos sistemas de saúde pública.

Levando em consideração todo conteúdo selecionado para realizar a elaboração desta revisão integrativa, é de grande valia que trabalhos futuros venham abordar assuntos como este, principalmente de forma prática, afim estabelecer resultados mais próximos dos valores reais. Pesquisas práticas voltadas a esse assunto, agregam dados que garantem uma seguridade tanto no meio de saúde quanto no meio científico para o consumo de alimentos.

\section{Referências}

Aarestrup, F. M., Hendriksen, R. S., Lockett, J., Gay, K., Teates, K., McDermott, P. F., White§, D. G., Hasman, H., Sørensen, G., Bangtrakulnonth, A., Pornreongwong, S., Pulsrikarn, C., Angulo, F. J., \& Gerner-Smidt, P. (2007). International spread of multidrug-resistant Salmonella Schwarzengrund in food products. Emerging infectious diseases, 13(5), 726. https://dx.doi.org/10.3201\%2Feid1305.061489

Abreu, I. M. D. O., Junqueira, A. M. R., Peixoto, J. R., \& Oliveira, S. A. D. (2010). Qualidade microbiológica e produtividade de alface sob adubação química e orgânica. Food Science and Technology, 30, 108-118. https://doi.org/10.1590/S0101-20612010000500018.

Andreotti, A., Baleroni, F. H., Paroschi, V. H., \& Panza, S. G. A. (2003). < b> Importância do treinamento para manipuladores de alimentos em relação à higiene pessoal. Iniciação Científica Cesumar, 5(1), 29-33.

Arbos, K. A., Freitas, R. J. S. D., Stertz, S. C., \& Carvalho, L. A. (2010). Segurança alimentar de hortaliças orgânicas: aspectos sanitários e nutricionais. Food Science and Technology, 30, 215-220.

Assis, R. L. D., \& Romeiro, A. R. (2007). O processo de conversão de sistemas de produção de hortaliças convencionais para orgânicos. Revista de Administração Pública, 41, 863-885. https://doi.org/10.1590/S0101-20612010000500033.

Bier, D., Silva, M. R., Ramos, C. A. D. N., Moriningo, G. D. A., Silva, T. A. D. S., Lima, A. C. D., \& Araújo, F. R. D. (2017). Survey of verotoxin-producing Escherichia coli and faecal coliforms in beef carcasses destined for export at slaughterhouses in Brazil. Food Science and Technology, 38, 60-66. DOI: https://doi.org/10.1590/1678-457X.37816.

Brasil. Ministério da Saúde. Agência Nacional de Vigilância Sanitária (ANVISA). Resolução da Diretoria Colegiada - RDC no 12 , de 2 de janeiro de 2001, dispõe sobre Regulamento técnico sobre padrões microbiológicos para alimentos. https://www.gov.br/agricultura/pt-br/assuntos/inspecao/produtosvegetal/legislacao-1/biblioteca-de-normas-vinhos-e-bebidas/resolucao-rdc-no-12-de-2-de-janeiro-de-2001.pdf/view

Brasil. Ministério da Saúde. Agência Nacional de Vigilância Sanitária (ANVISA). Instrução Normativa $N^{\circ} 60$, DE 23 De Dezembro De 2019, estabelece as listas de padrões microbiológicos para alimentos. https://www.in.gov.br/en/web/dou/-/instrucao-normativa-n-60-de-23-de-dezembro-de-2019-235332356

Brasil. Ministério da Saúde. Biblioteca Virtual em Saúde do Ministério da Saúde (BVSMS). Cuidados Com Os Alimentos Para Consumo Humano Em Situações De Enchentes.1, 2014. bvsms.saude.gov.br/bvs/folder/cuidado_alimentos_consumo_humano_2014.pdf

Cardoso, T. G., \& de Carvalho, V. M. (2006). Toxinfecção alimentar por Salmonella spp* Foodborne disease caused by Salmonella spp. Journal of the Health Sciences Institute, 24(2), 95-101. 
Costa, C. A. R. (2010). Avaliação da exposição do consumidor à Listeria monocytogenes, Salmonella spp., Campylobacter spp. e Escherichia coli produtora de toxina de Shiga em produtos cárneos refrigerados comercializados no município de São Paulo (Doctoral dissertation, Universidade de São Paulo). https://doi.org/10.11606/T.9.2010.tde-09042010-140456.

da Silva, N., Junqueira, V. C. A., de Arruda Silveira, N. F., Taniwaki, M. H., Gomes, R. A. R., \& Okazaki, M. M. (2017). Manual de métodos de análise microbiológica de alimentos e água. Editora Blucher.

Ercole, F. F., Melo, L. S. D., \& Alcoforado, C. L. G. C. (2014). Revisão integrativa versus revisão sistemática. Revista Mineira de Enfermagem, 18(1), 9-12. DOI: http://www.dx.doi.org/10.5935/1415-2762.20140001.

Estrela, C., Estrela, C. R., Barbin, E. L., Spanó, J. C. E., Marchesan, M. A., \& Pécora, J. D. (2002). Mechanism of action of sodium hypochlorite. Brazilian dental journal, 13, 113-117. DOI: https://doi.org/10.1590/S0103-64402002000200007.

Ferreira, C. C., Gregório, E. L., Costa, J. D., de Paula, R. B. O., de Araujo Neta, H. A. G., \& Fontes, M. D. (2016). Análise de coliformes termotolerantes e Salmonella sp. em hortaliças minimamente processadas comercializadas em Belo Horizonte-MG. HU Revista, 42(4), $307-313$.

Franco, B. D. G. M.; Landgraf, M. Microbiologia dos alimentos. Atheneu, 2001. 192 p.

Hoffmann, F. L. (2001). Fatores limitantes à proliferação de microorganismos em alimentos. Brasil Alimentos, 9(1), 23-30.

Jorge, R. Cinco Chaves Para Uma Alimentação Mais Segura. Edição Organização Mundial de Saúde, 2006. https://www.who.int/foodsafety/consumer/5KeysManual_pt.pdf.

Kaper, J. B., Nataro, J. P., \& Mobley, H. L. (2004). Pathogenic escherichia coli. Nature Reviews Microbiology, 2(2), 123-140. https://doi.org/10.1038/nrmicro818.

Keskinen, L. A., Burke, A., \& Annous, B. A. (2009). Efficacy of chlorine, acidic electrolyzed water and aqueous chlorine dioxide solutions to decontaminate Escherichia coli O157: H7 from lettuce leaves. International Journal of Food Microbiology, 132(2-3), 134-140. https://doi.org/10.1016/j.ijfoodmicro.2009.04.006.

Lanza, J. Surtos alimentares no Brasil. Food Safety Brasil: segurança de alimentos. 2016. https://foodsafetybrazil.org/surtos-alimentares-no-brasil-dadosatualizados-em-maio-de-2017/

Martins, I. A., Vieira, A. C., Machado, J. M. S., Gregório, E. L., \& do Amaral, D. A. (2021). Análise microbiológica de hortaliças e vegetais minimamente processados comercializados em grandes redes de supermercados de Belo Horizonte-MG. Brazilian Journal of Health Review, 4(1), 1172-1185. https://doi.org/10.34119/bjhrv4n1-104.

Maziero, M. T., \& Bersot, L. D. S. (2010). Micotoxinas em alimentos produzidos no Brasil. Revista Brasileira de Produtos Agroindustriais, 12(1), 89-99. https://doi.org/10.15871/1517-8595/rbpa.v12n1p89-99.

Murphy, P. A., Hendrich, S., Landgren, C., \& Bryant, C. M. (2006). Food mycotoxins: an update. Journal of food science, 71(5), R51-R65.

Nascimento Neto, F. D. (2006). Recomendações básicas para a aplicação das boas práticas agropecuárias e de fabricação na agricultura familiar. Embrapa Agroindústria de Alimentos-Livro técnico (INFOTECA-E).

Prado, S. D. P. T., Ribeiro, E. G. A., Capuano, D. M., de Aquino, A. L., de Melo Rocha, G., \& Bergamini, A. M. M. (2008). Avaliação microbiológica, parasitológica e da rotulagem de hortaliças minimamente processadas comercializadas no município de Ribeirão Preto, SP/Brasil. Revista do Instituto Adolfo Lutz, 67(3), 221-227.

Rocha, M. M., de Albuquerque Sousa, M. A., de Sousa, R. D. S., Arcanjo, S. R. S., Parreira, C. R., \& de Oliveira, A. M. C. (2015). Qualidade microbiológica de hortaliças folhosas comercializadas em picos-pi. Higienistas Alimentares Reunem-se em Búzios, RJ., 29(242/243), 130.

Shinohara, N. K. S., Barros, V. B. D., Jimenez, S. M. C., Machado, E. D. C. L., Dutra, R. A. F., \& Lima Filho, J. L. D. (2008). Salmonella spp., importante agente patogênico veiculado em alimentos. Ciência \& saúde coletiva, 13, 1675-1683. https://doi.org/10.1590/S1413-81232008000500031.

Silva, M. P., Cavalli, D. R., \& Oliveira, T. C. R. M. (2006). Avaliação do padrão coliformes a $45^{\circ} \mathrm{C}$ e comparação da eficiência das técnicas dos tubos múltiplos e Petrifilm EC na detecção de coliformes totais e Escherichia coli em alimentos. Food Science and Technology, 26, 352-359. https://doi.org/10.1590/S0101-20612006000200018.

Tabela Brasileira de Composição de Alimentos (TACO). $4^{a}$ Edição revisada $e$ ampliada. Campinas, SP: UNICAMP; 2011. https://www.cfn.org.br/wpcontent/uploads/2017/03/taco_4_edicao_ampliada_e_revisada.pdf.Acesso em: 26 mai. 21

Teixeira, L. E. B., dos Santos, J. E. F., dos Santos Moreira, I., de Sousa, F. C., \& Nunes, J. S. (2013). Qualidade microbiológica de frutas e hortaliças comercializadas na cidade de Juazeiro do Norte, CE. Revista Verde de Agroecologia e Desenvolvimento Sustentável, 8(3), 6.

Tresseler, J. F. M., Figueiredo, E. A. T. D., Figueiredo, R. W. D., Machado, T. F., Delfino, C. M., \& Sousa, P. H. M. D. (2009). Avaliação da qualidade microbiológica de hortaliças minimamente processadas. Ciência e Agrotecnologia, 33, 1722-1727. https://doi.org/10.1590/S1413-70542009000700004. 